hours immediately preceding death were not made, and further evidence is required before their effect can be assessed adequately.

We are grateful to the Registrar General for providing us with copies of the death entries relating to young persons who had died of asthma, to the many doctors and coroners who replied to our questions and made their records available to us, and to Mrs. Ranjana Ash for help in coding and analysing the data.
Dr. F. E. Speizer was supported by the National Center for Air Pollution, Bureau of Disease Prevention and Environmental Control, U.S. Public Health Service.

\section{REFERENCES}

Daly, J. J., and Howard, P. (1965). Thorax, 20, 324

Field, G. B. (1967). Clin. Sci., 32, 279.

Knudson, R. J., and Constantine, H. P. (1967), F. appl. Physiol., 22, 402

Palmer, K. N. V., and Diament, M. L. (1967). Lancet, 2, 383

Speizer, F. E., Doll, R., and Heaf, P. (1968). Brit. med. F., 1, 335

\title{
Some Problems of Permanent Artificial Pacing*
}

\author{
M. S. GOTSMAN, M.D., M.R.C.P., M.R.C.P.GLASG. ; L. W. PILLER, F.S.C.T. ; W. BECK, M.MED., M.SC., M.R.C.P. \\ C. N. BARNARD, D.SC., M.D., M.MED., M.S., PH.D., F.A.C.S. \\ V. SCHRIRE, M.D., M.SC., PH.D., F.R.C.P., F.R.C.P.ED., F.A.C.C.
}

Brit. med. 9., 1968, 1, 343-346

Patients with complete heart block who have symptoms which cannot be controlled by sympathomimetic amines or vagolytic drugs are best treated by artificial pacing (Chardack, Gage, Federico, Schimert, and Greatbatch, 1964 ; Bluestone, Davies, Harris, Leatham, and Siddons, 1965 ; Gotsman, Beck, Barnard, and Schrire, 1966 ; Furman, Escher, Schwedel, and Solomon, 1966 ; Lagergren, 1967 ; Parsonnet, Zucker, Gilbert, Brief, and Alpert, 1967).

Though many different systems have been devised and used, sach method has its own particular advantages and problems. Experience with the various techniques is accumulating from many countries, but the limiting factors are battery exhaustion, failure of electronic components, fatigue of electrode wires or insulation, or biological reaction to an implanted system Sowton and Davies, 1964 ; Davies and Siddons, 1965 ; Glass, 1965).

We describe our own methods and experience to show that pacing is relatively safe and that it is possible to treat patients who live far from the major cardiac clinic or consultant medical services.

\section{Patients}

Permanent artificial pacing was undertaken in 48 patients with complete heart block. Five had intermittent complete heart block but were treated for Stokes-Adams attacks. Twelve patients were in severe heart failure, three had symptoms of severe cerebrovascular insufficiency due to a low cardiac output which was improved by an artificial increase in heart rate, and the remainder had repeated incapacitating Stokes-Adams attacks. Seven patients had a previous proved myocardial infarction (Gotsman, Beck, Piller, and Schrire, 1967 ; Davies, Redwood, and Harris, 1967), one had toxoplasmosis, another had complete heart block before repair of an endocardial cushion defect, while in the remainder an obvious cause could not be found. They were older subjects, and we presume that the block was due to fibrosis of the cardiac skeleton (Lenègre and Moreau, 1963 ; Lev, 1964). Nearly all the patients were given an initial trial of medical treatment with atropine, ephedrine, and long-acting isoprenaline. Pacemaking was not used in 20 other patients with complete heart block who were free of symptoms or had symptoms which could be controlled by drug therapy.

- From the Cardiac Clinic, Departments of Medicine and Surgery, Groote Schuur Hospital, and the Cardiovascular Pulmonary Research Group, University of Cape Town. Supported in the Department of Medicine by the Council for Scientific and Industrial Research.

\section{Techniques}

Ninety-one units were implanted in 48 patients in the three and a half years from July 1964 to November 1967. We elected to use a totally implanted system, as patients preferred not to have exteriorized wires and external generators. Six different systems were used; with each change we improved the weak link of the previous method. This was done only when the weak link became obvious, and the revised technique was then used in all subsequent replacements. The results are summarized in the Table, which shows the different systems used arranged in chronological sequence, the number of units used, the time range and mean duration of each satisfactory implant, and the causes of pacemaker failure in each case.

(1) Epicardial Electrodes with an Abdominal Implanted Generator (Elema E.M. $139^{1}$ or Devices $A^{2}$ ).-Eight units were implanted in seven patients. This system was unsatisfactorythe electrode wires fractured or became detached from the heart and bradycardia occurred, often with recurrent life-threatening Stokes-Adams attacks. The patients needed urgent readmission to hospital for an alternative system of pacing. In six of the eight cases the wires broke or became detached after 1 to 12 months, with a mean duration of successful pacing of four months.

(2) Transvenous Pacemaking Wire (U.S.C.I. C50 ${ }^{3}$ with an Axillary Generator (Devices $A$ or $X^{2}$ ).-An endocardial wire was used to avoid epicardial wire detachment. Seventeen units were inserted during a six-month period from November 1964. The generators manufactured at that time proved unreliable and battery or component failure occurred after 4 to 10 months in seven patients ; the mean duration of generator life was six months. In three other patients either the electrode wire fractured or the insulation covering cracked in the neck, producing failure after 5 to 10 months (mean, six months). Perforation of the ventricle occurred in two patients, two units failed because of exit block, and three other patients died of other causes (see Table). The "weak link," the Devices generator, was therefore replaced by the Elema unit.

(3) Transvenous Pacemaking Wire (U.S.C.I. C50) with an Axillary or Abdominal Generator (Elema E.M. 139).-Eight units were implanted. In six the outer insulating covering of the U.S.C.I. electrode wire fractured in the neck from repeated flexion stresses (Fig. 1). This short-circuited the output of

\footnotetext{
${ }^{1}$ Elema-Schönander, Stockholm, Sweden.

${ }^{2}$ Devices Ltd., Welwyn Garden City, Herts, England.

- United States Catheter Corporation, Glen Falls, U.S.A.
} 
the generator with loss of pacing, sudden bradycardia, and usually an acute emergency situation until the unit could be replaced. The wires lasted from 2 to 15 months, with a mean of 10 months. Components in the generator failed after 7 and 14 months. This system also had three other major disadvantages. The wire and generator were inserted at the same time,

FIG. 1.-Insulation fracture of a C50 pacemaking electrode wire (U.S.C.I.). The insulation cover fractured in the neck (arrow).

so that an initial temporary transvenous wire was often needed to control the heart rate. It also meant that we could measure the electrical threshold for pacing only when the wire was inserted and that initial fluctuations could not be detected. Furthermore, the hard wire transmitted neck movements to the tip, so that displacement was common. The tip either perforated the heart or was withdrawn into the right atrium. Again this caused sudden loss of pacing and we had to reposition the wire on 15 occasions in 12 patients; this was needed twice in three patients. Usually it occurred within the first fortnight after implantation, often in the first 48 hours. Once it happened six months after insertion. Bluestone et al. (1965) reported similar complications with this wire. The wire was the weak link in the system: displacement of the tip was a minor troublesome fault, but insulation failure needed replacement of the wire.

(4) Transvenous Pacemaking Wire (Elema E.M.T. 570 or 588) with an Abdominal Generator (E.M. 139).-We felt that the U.S.C.I. electrode wire was unsuitable and replaced it with a stronger but softer and more flexible wire. Fifty units have been inserted since March 1966. The wire and generator were then inserted in two stages; the details have been reported elsewhere (Lagergren, Johansson, Landegren, and Edhag, 1965 ;
Gotsman, Beck, Piller, Bosman, Barnard, and Schrire, 1966). The wire was inserted first by using gravity and radiological control. An additional temporary transvenous wire was unnecessary and it was possible to measure and assess changes in the electrical threshold for pacing over the next 4 to 14 days. When this was stable the permanent generator was inserted, usually after 4 to 14 days. This system has been trouble-free, but the generator batteries have failed after 15 to 19 months. We are now replacing the generator electively after 15 to 18 months unless premature decay of the battery output is detected (see Table).

(5) Transvenous Bipolar Pacemaking Wire (Medtronic 5816) with an Axillary Generator (Medtronic 5860) (three units) or Elema wire (two units).-The unit has a soft, durable bipolar electrode wire with a removable guide wire which simplifies insertion. The generator has a longer life than the E.M. 139 The wire and generator are inserted at the same time, so that initial changes in the pacing threshold cannot be assessed. The three complete Medtronic units were inserted in December 1965 to compare them with method 4 . We removed one generator prophylactically after 21 months because $x$-ray studies suggested battery exhaustion (Lillehei, Cruz, Johnsrude, and Sellers, 1965). Tests of the generator after removal showed that the output of the battery was normal. In another patient the heart rate increased by five beats per minute after 21 months. The generator was removed and the change in rate was due to battery exhaustion. We prefer the staged technique of system 4 and the longer life of the Medtronic generator, and we have now used this generator with the E.M.T. 588 wire inserted as a two-stage procedure in two patients. The variable output of the Medtronic $5870 \mathrm{C}$, which can be adjusted according to the patient's threshold for pacing, promises a longer generator life. In either system only the generator needs replacement when failure occurs or is anticipated. This is a minor procedure which, if needed, can be done under local anaesthesia to avoid the circulatory hazards of general anaesthesia in patients with a slow, fixed heart rate.

- Medtronic Inc., Minneapolis, U.S.A.

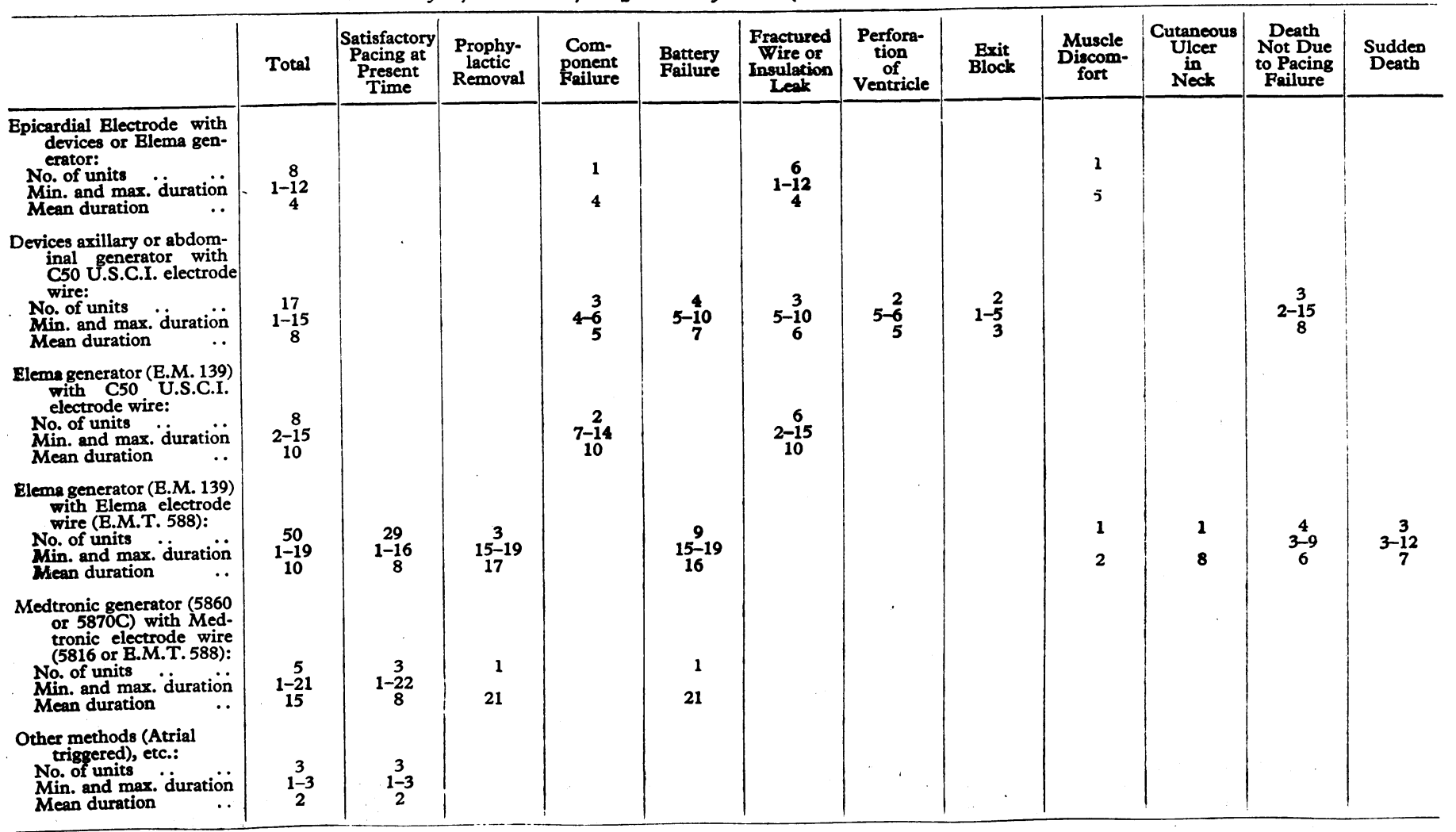


(6) Atrial Triggered Pacemaker Generator (Elema E.M. 141) with an Endocardial Pacemaking Wire (E.M.T. 588) for stimulation and a second wire in the pericardial space near the right atrium to detect atrial depolarization. Our experience with this method is limited to two patients, and its reliability has to be proved (Gotsman, Barnard, and Schrire, 1968).

\section{Deaths}

Ten patients died. In six this was due to associated disease such as carcinoma. One patient had a progressive increase in heart rate due to component failure of the generator; she would not allow the generator to be replaced. Three patients collapsed and died suddenly ; two had had previous extensive myocardial infarctions, and death was probably due to ventricular fibrillation; both had been in intermittent sinus rhythm before this happened, the electrode wires were in a good position at necropsy, and the generators were working well (Fig. 2). The third patient was in sinus rhythm but had intermittent heart block and Stokes-Adams attacks. Again the pacemaker wire was in a good position and the generator was normal. There was no obvious cause of death. Death in these three patients must have been due to sudden ventricular fibrillation from an inappropriately timed pacemaker stimulus in a patient who was in sinus rhythm (Sowton, 1965).

\section{Detection of Impending Pacemaker Failure : the Pacemaker Clinic}

Pacemaking may fail because of generator failure, wire failure, biological reaction to implanted materials, and exit block

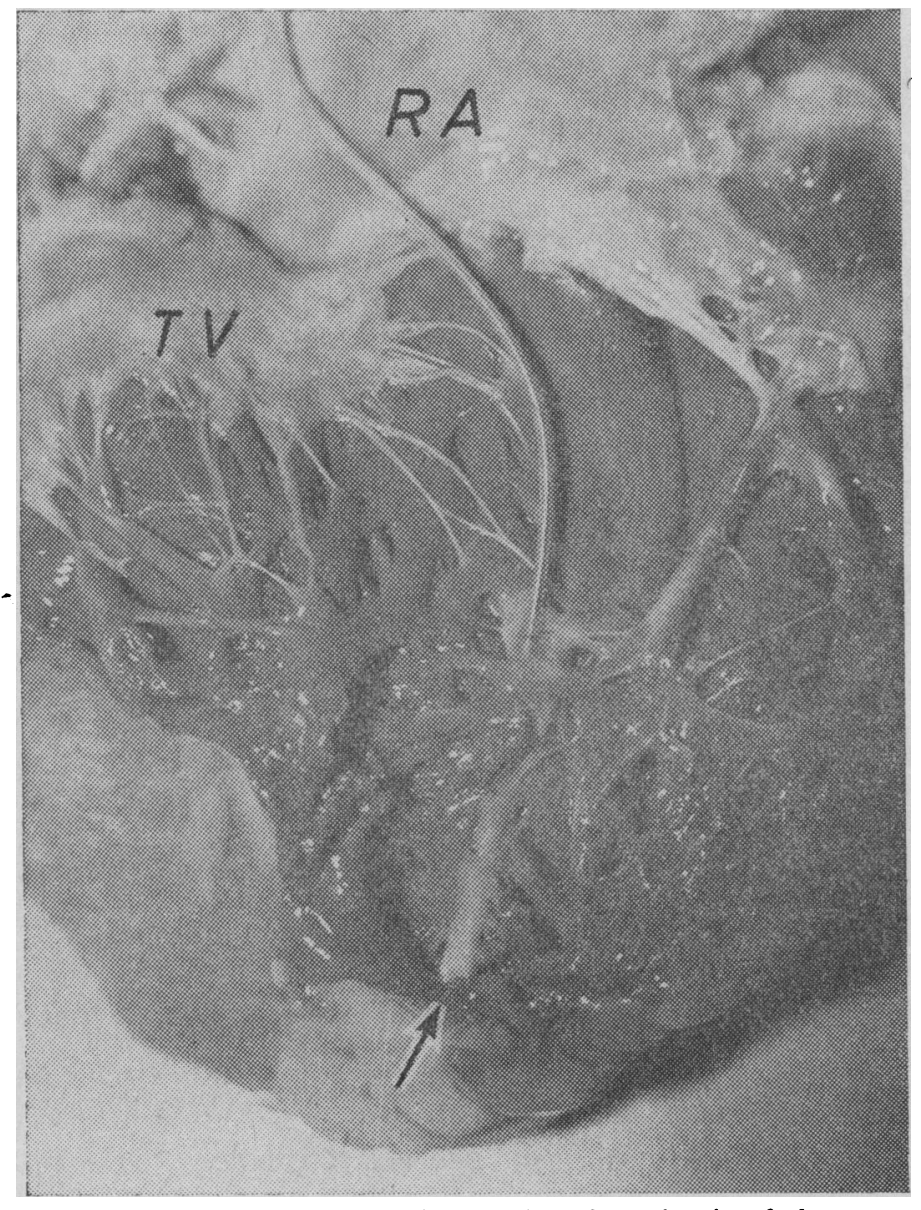

FIG. 2.- Interior of right ventricle to show how the tip of the pacemaking electrode wire is incorporated into the trabeculae and endocardium (arrow). The wire passes through a commissure of the tricuspid valve (TV) and is endothelialized and attached to the wall of the right atrium (RA).
(Davies and Siddons, 1965). Patients with pacemakers can be managed in three ways: waiting for the unit to fail, elective replacement of part or all of the unit before its useful life has expired, or regular electronic measurements at a pacemaking clinic to detect impending failure (Sowton, 1967).

We have used all three methods and have varied our technique to avoid sudden failure and to find a system which has the longest wire and generator life. Sudden failure exerts a profound psychological effect on the patient, who then has residual anxiety about future failure and its associated hazards. Thus epicardial electrode fracture or detachment was unpredictable ; the technique was therefore abandoned in favour of transvenous pacing, which also avoided thoracotomy. Component failure or premature battery exhaustion was common with the Devices generators; they were replaced by the Elema and Medtronic generators, which were more reliable and had a longer life; both have given good service, but the latter lasts longer. The U.S.C.I. C50 wire became the weak link because insulation fracture produced an electrical short-circuit and sudden unexpected pacing failure. The Elema (E.M.T. 588) and Medtronic (5816) wires have lasted for two years without trouble and have proved to be durable. Many wires are now being used with their second generator.

\section{Exit Block}

Exit block has been avoided by a carefully planned two-stage procedure. The tip of the electrode wire is placed at the apex of the right ventricle, in a position of maximum stability, but where the threshold is less than 1 volt. In a few patients the endocardium has been relatively insensitive, though the wire tip was placed in several different positions and the minimum threshold was more than 2 volts. We then measured the minimum threshold for two weeks. Patients with initial threshold of less than 1 volt, which did not increase after four days, showed no further change. In these patients the generator can be implanted after four to five days. However, if the initial threshold is high or it rises we defer implantation until a plateau is reached. In one patient with a high threshold we implanted the generator but had to reposition the wire later because of exit block. In another we altered the position of the wire before final implantation. Since then we have not had exit block and we rarely wait more than two weeks before implanting the generator. A late rise in threshold is uncommon -in six patients we measured the threshold for pacing when the permanent generator was replaced; there had been no change since implantation. This waiting period has another advantage: the wire tip becomes anchored to the endocardium of the right ventricle and later displacement is unlikely (Fig. 2).

\section{Generator Failure}

Generator failure from battery exhaustion is our present weak link and we try to predict impending battery failure by assessing the patients regularly at a pacemaking clinic. Premature battery exhaustion is suggested by a change in heart rate, decay ratio, duration of impulse, or a fall in stimulus amplitude at the limbs (Sowton, 1967). We have measured only the heart rate and the stimulus amplitude at the limbs. Standard leads of the electrocardiogram were recorded on a photographic recorder to prevent distortion inherent in a direct-writing system. The voltage of the stimulating impulse (spike potential) was then measured in each lead and the magnitude of the resultant spike vector calculated. Typical changes are shown in Fig. 3. Minor changes were noted three to four months before battery failure occurred, and the size of the vector decreased as battery exhaustion approached. We removed the generator when the spike potential had fallen to $60 \%$ of control value. This depends on the endocardial threshold for pacing, and pacing fails when the output of the generator falls below the threshold value. These 
patients with a low threshold have a greater margin of safety than patients with a high threshold. We allowed a greater decrease to occur in one patient, and pacing failed. This technique of testing is more difficult with the bipolar wire (5816), and here we have relied on $x$-ray studies of the generator to detect impending battery failure (Lillehei et al., 1965).

Initially we saw our patients at monthly intervals and made elaborate tests of pacemaker function, but it soon became obvious that measurement of heart rate, spike vector amplitude in a unipolar system, and radiology of the battery of the Medtronic generator were sufficient to detect impending failure. At present we see patients one, six, 12 , and 15 months after implantation of the generator. Thereafter they are seen at monthly intervals, depending on the fall in spike potential. The generator is replaced when the magnitude of the vector has tallen to $60 \%$ of control value. Patients who live far away from the clinic-many live 500 to 2,000 miles ( 800 to $3,200 \mathrm{~km}$.) away-are seen at 12 or 15 months only. We request a routine electrocardiogram at six months, and they are warned to report any change in heart rate. In these patients we prefer to change the Elerna generator electively at the end of 15 months and the Medtronic generator after 21 months.

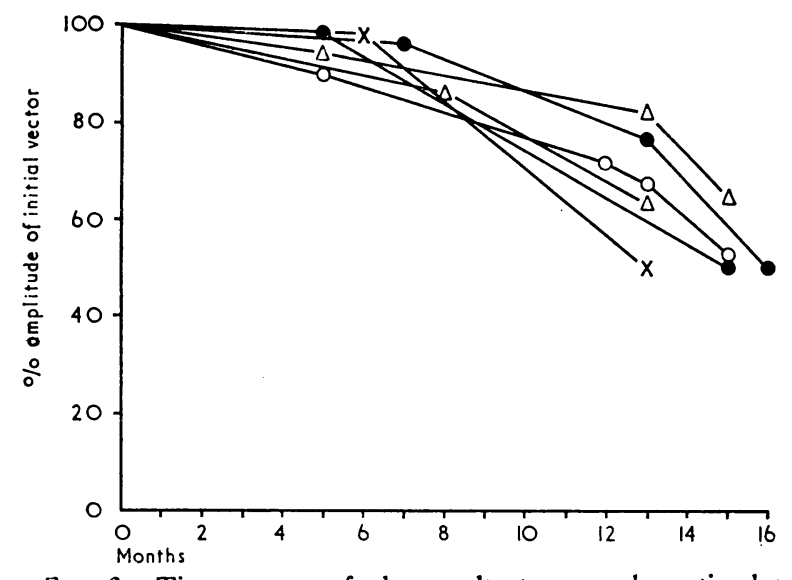

FIG. 3.-Time course of the resultant pacemaker stimulus rector measured in the limb leads in patients with an Elema B. 139 generator. Values are expressed as a percentage of ..M. he initial vector at the time of generator implantation. There is a slow initial decay which becomes more rapid as battery
exhaustion occurs. The generator is renewed when the magnitude of the vector is less than $60 \%$ of control value.

\section{General Conclusions}

We have found the transvenous system of pacemaking safe and reliable and have abandoned thoracotomy to attach epicardial pacemaking wires. The Elema and Medtronic electrode wires have given two years of trouble-free service, but with the former the unit is inserted in two stages and the position of the tip of the wire can be altered before the generator is inserted. The present "weak link" is generator failure. Sudden failure can be avoided by regular testing of the generator battery when exhaustion is anticipated or by elective replacement in patients who live a long way from the clinic. Thus patients who live locally are watched carefully after the first year of implantation if they have an Elema generator and after 18 months if they have a Medtronic generator. Elective replacement means that some pacemakers are removed before the end of their useful life, but this method is so much safer ; it avoids sudden failure and the need for repeated electrical checks, which are inconvenient for patients who live far away. Sudden component failure can still occur at any time and patients are warned about this.
All our patients wear an armband to show that they have an implanted pacemaker ; they carry a supply of sublingual and long-acting isoprenaline, and relatives are instructed about thumping the chest-a life-saving treatment for asystole.

We have also used "atrial-triggered" and "on demand" pacemakers in three patients, but our experience with these units is limited. Reliable "on demand" units will replace fixed-rate ventricular stimulation in patients with intermittent complete heart block.

Artificial pacemaking has greatly improved the quality of these patients' lives, and our results have been most rewarding despite the initial technical difficulties and the need for a 24-hour emergency service. With experience, emergency admissions have become uncommon.

We believe that pacemaking should be recommended for any patient who has symptoms from complete heart block, even if he lives 2,000 miles $(3,220 \mathrm{~km}$.) away from the major cardiac centre.

\section{Summary}

We inserted 91 pacemaking units in 48 patients. Six different systems were used. Each technique improved the "weak link" of the previous method: epicardial electrode wire detachment, premature generator or battery failure, and electrode wire insulation fracture. We use the Elema E.M.T. 588 wire with an Elema E.M. 139 generator, or Medtronic 5816 wire with a 5860 or $5870 \mathrm{C}$ generator. The Elema generator lasts for 15 months, whereas the Medtronic units have lasted for longer than 21 months. Patients require minimal follow-up if they are warned about the hazards and treatment of sudden pacemaker failure. Measurements of the heart rate and the change in amplitude of the stimulating vector as measured in the standard leads are simple guides to anticipate battery exhaustion. Elective replacement is undertaken if the patient lives far from the major cardiac centre.

We are grateful to our colleagues who referred patients for treatment; to Dr. J. G. Burger, Superintendent of Groote Schuur Hospital, for permission to publish; and to the South African Council for Scientific and Industrial Research and the City Counci) of Cape Town for financial support.

\section{REFERENCES}

Bluestone, R., Davies, G., Harris, A., Leatham, A., and Siddons, $\mathbf{H}$. (1965). Lancet, 2, 307.

Chardack, W. M., Gage, A. A., Federico, A. J., Schimert, G., and Greatbatch, W. (1964). Ann. N.Y. Acad. Sci., 111, 1075.

Davies, J. G., and Siddons, H. (1965). Thorax, 20, 128

Davies, M. J., Redwood, D., and Harris, A. (1967). Brit. med. f., 3, 342 Furman, S., Escher, D. J. W., Schwedel, J. B., and Solomon, N. (1966) Amer. Heart f., 71 , 408.

Glass, H. I. (1965). In Proceedings of Conference on Resuscitation and Cardiac Pacing, edited by G. Shaw, G. Smith, and J. J. Thomson. p. 207. London.

Gotsman, M. S., Barnard, C. N., and Schrire, V. (1968). In preparation Beck, W., Barnard, C. N., and Schrire, V. (1966). South Afr. med. f., 40, 607 .

Piller, L. W., Bosman, S. C. W., Barnard, C. N., and Schrire, V. (1966). Brit. med. $尹$., 2, 1357.

Lagergren, H. (1967). Israel f. med. Sci., 3, 216. Johansson, L., Landegren, J., and Edhag, O. (1965). f. thorac cardiovasc. Surg., 50, 710 .

Lenègre, J., and Mcrau, P. (1963). Arch. Mal. Cour, 56, 867.

Lev, M. (1964). Amer. F. Med., 37, 742.

Lillehei, C. W., Cruz, A. B., Johnsrude, I., and Sellers, R. D. (1965) Amer. F. Cardiol., 16, 717.

Parsonnet, V., Zucker, I. R., Gilbert, L., Brief, D. K., and Alpert, J. (1967). Israel f. med. Sci., 3, 210.

Sowton, E. (1965). Brit. Heart f., 27, 311.

— and Davies, J. G. (1964). Brit. med. F., 1, 1470. 